\title{
PENGUAT AUDIO KELAS D DENGAN UMPAN BALIK TIPE BUTTERWORTH
}

\author{
Gunawan Dewantoro*, Franciscus Dalu Setiaji, Tio Pragustha \\ Program Studi Teknik Elektro, Fakultas Teknik Elektronika dan Komputer \\ Universitas Kristen Satya Wacana \\ *Corresponding author, e-mail : gunawan.dewantoro@staff.uksw.edu
}

\begin{abstract}
Abstrak-Proses penguatan sinyal pada penguat kelas D idealnya tidak terdapat derau dan distorsi sehingga penguat kelas D dapat menghasilkan efisiensi hingga $100 \%$ dan THD (Total Harmonic Distortion) 0\%. Namun pada praktisnya, penguat kelas D memiliki beberapa kekurangan yang menyebabkan keluaran penguat kelas D menjadi tidak linear sehingga mengakibatkan naiknya THD. Oleh karena permasalahan tersebut, diberikan sutau mekanisme umpan balik negatif yang dapat memperbaiki kualitas THD dari penguat. Beberapa teknik umpan balik negatif menggunakan tapis orde 1 pada umpan balik untuk mendapatkan frekuensi audio. Penelitian ini merancang teknik umpan balik negatif menggunakan tapis orde 2 dengan pendekatan Butterworth. Penguat daya diwujudkan menggunakan penguat jembatan penuh dengan MOSFET yang dapat menghasilkan daya lebih besar. Penguat kelas D yang dibuat mempunyai spesifikasi antara lain: daya keluaran maksimum mencapai 32,6 Watt pada beban $8 \Omega$, dengan kepekaan penguat $90 \mathrm{mV} / \mathrm{W}$, memiliki tanggapan frekuensi $20 \mathrm{~Hz}-20 \mathrm{kHz}$ dengan toleransi $\pm 1 \mathrm{~dB}$, THD dengan umpan balik mencapai $1,1 \%$, SNR hingga 90,16 dB serta efisiensi penguat mencapai $82,1 \%$.
\end{abstract}

\section{Kata Kunci : Penguat Kelas D, Umpan Balik, Butterworth, Total Harmonic Distortion}

\begin{abstract}
A class D amplifier would, in ideal sense, amplify signals without any noises and distortions which yield 100\% efficiency and 0\% Total Harmonic Distortion (THD). However, class D amplifiers have some drawbacks that lead to nonlinearity and increasing THD. Therefore, a feedback mechanism was employed to enhance THD performance of amplifier. Some feedback techniques have been using first order filter in the feedback path to retrieve audio signals. This research proposed a second order filter with Butterworth approach. A power amplifier was realized using full-bridge amplifier with MOSFETs to provide greater power. This class D amplifier was designed to meet following specifications: maximum output power up to $32.6 \mathrm{~W}$ with an $8 \Omega$ load, sensitivity of $90 \mathrm{mV} / \mathrm{W}$, frequency response ranging from 20 $\mathrm{Hz}-20 \mathrm{kHz}$ with tolerance $\pm 1 \mathrm{~dB}$, THD as low as $1.1 \%$, SNR up to $90.16 \mathrm{~dB}$, and efficiency of $82.1 \%$.
\end{abstract}

Keywords : Class D Amplifier, Feedback, Butterworth, Total Harmonic Distortion

Copyright $@ 2016$ JNTE. All rights reserved

\section{PENDAHULUAN}

Penguat kelas D yang ideal tidak terdapat distorsi dan tidak ada derau pada pita audio. Akan tetapi pada praktisnya penguat kelas D terdapat distorsi dan derau yang dihasilkan pada proses penyaklaran yang tidak ideal diakibatkan pada bagian MOSFET atau transistor bekerja tidak pada daerah linearnya. Secara teori semakin linear penguat maka semakin berkurang distorsi dengan kata lain distorsi harmonik (THD) yang dihasilkan semakin kecil [1], [2]. Salah satu teknik untuk menghasilkan penguat kelas D dengan THD kecil adalah penggunaan umpan balik digital yang telah dilakukan oleh Nielsen, teknik modulasi dengan sigma delta [3], [4], teknik bitstream converter yang membutuhkan oversampling yang tinggi (256x) dan lain sebagainya [5]. Beberapa faktor yang mempengaruhi kualitas audio adalah distorsi (THD) dan derau (SNR) [6]. Masalah pada penguat kelas $\mathrm{D}$ tanpa umpan balik adalah kerentanan modulator dan penguat penyaklaran pada ketidaklinearan akibat distorsi dan derau.

Oleh karena itu, pada penelitian ini dirancang sebuah penguat kelas D yang dapat memperbaiki kualitas THD dengan memberikan umpan balik negatif. Sinyal masukan umpan balik memiliki karakteristik frekuensi tinggi karena terdiri dari sinyal audio dengan frekuensi 
rendah dan sinyal pembawa yang merupakan frekuensi tinggi. Untuk mendapatkan sinyal audio ini diberikan tapis lolos bawah pada umpan balik dan tapis yang dirancang adalah tapis lolos bawah orde 2 dengan tipe Butterworth. Tapis lolos bawah tipe Butterworth ini memiliki kelebihan yaitu penguatan yang rata pada pita lolosnya atau pada frekuensi rendah. Semakin tinggi orde dari tapis maka semakin baik umpan balik dapat menekan frekuensi-frekuensi tinggi pada umpan balik.

\section{PERANCANGAN}

Pada penelitian ini, penguat audio kelas D dirancang dengan memberikan umpan balik negatif yang dapat dilihat pada Gambar 1. Umpan balik negatif pada penguat kelas D ini terdiri dari penguat selisih, tapis lolos bawah orde 2 tipe Butterworth dan integrator penjumlah.

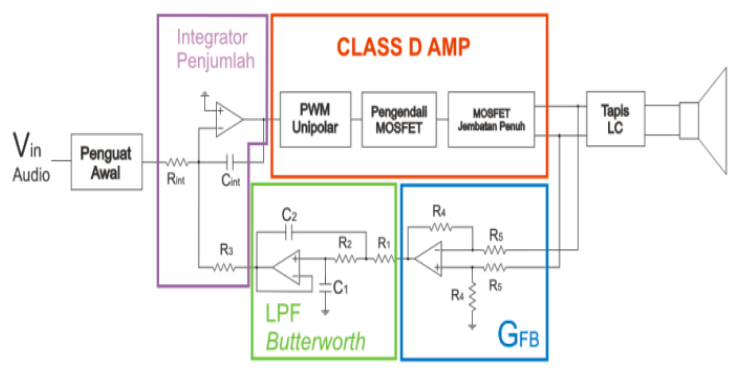

Gambar 1. Penguat Kelas D dengan Umpan Balik Tipe Butterworth.

Pada penguat kelas $\mathrm{D}$ tersebut terdapat penguat selisih $\left(\mathrm{G}_{\mathrm{FB}}\right)$ karena masukan umpan balik berasal dari keluaran penguat daya dengan konfigurasi jembatan penuh. Kemudian keluaran dari penguat selisih ditapis dengan tapis Butterworth untuk kemudian dibandingkan dengan sinyal audio aslinya dengan menggunakan integrator penjumlah. Penggunaan integrator dikarenakan integrator biasanya merupakan tapis lolos bawah sehingga keluaran dari tapis Butterworth frekuensifrekuensi tinggi dapat jauh lebih ditekan.

\subsection{Penguat Selisih}

Kestabilan penguat kelas D dengan umpan balik akan tercapai jika penguatan dari umpan balik < 1 [7]. Sehingga perancangan penguatan dari umpan balik $\mathrm{G}_{\mathrm{FB}}$ harus $<1$. Penguatan PWM pada bagian modulator kelas $\mathrm{D}$ adalah $\mathrm{G}_{\mathrm{PWM}}=$ 8,27 yang didapatkan dari perbandingan penguatan tegangan pada bagian penguat daya $(24 \mathrm{~V})$ dengan amplitudo sinyal segitiga $(2,9 \mathrm{~V})$. Untuk mendapatkan penguatan umpan balik $<1$ sinyal umpan balik perlu dilemahkan sebesar 8,4 kali, sehingga besar $\mathrm{G}_{\mathrm{FB}}=0,12$. Hal ini bertujuan agar penguatan kelas D pada rentang spektrum audio sama untuk penguat dengan umpan balik atau tanpa umpan balik.

Penguatan umpan balik dirancang dengan menggunakan penguat selisih, karena sinyal masukan umpan balik berasal dari keluaran MOSFET jembatan penuh. Untuk mendapatkan pelemahan sebesar 0,12 kali maka perancangan bati umpan balik dengan penguat selisih dapat dilihat pada Gambar 2 sebagai berikut :

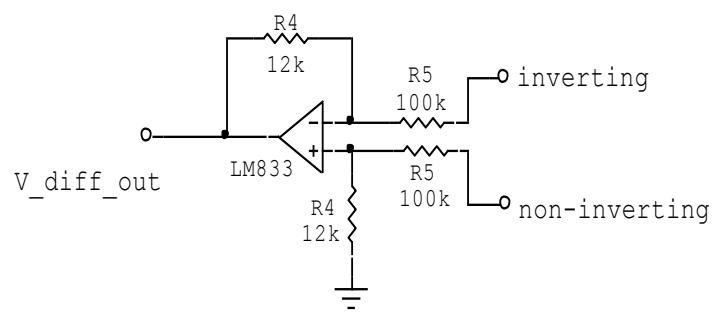

Gambar 2. Penguat Selisih dengan Pelemahan Sebesar 0,12.

Penguatan dari penguat selisih dapat dituliskan sebagai berikut:

$$
A_{v}=\frac{V_{\text {diff_out }}}{\left(V_{\text {non-inv }}-V_{\text {inv }}\right)}=\frac{R_{4}}{R_{5}}=0,12
$$

\subsection{Tapis Butterworth}

Terdapat 2 cara untuk dapat lebih menekan frekuensi tinggi dari umpan balik yaitu dengan membesarkan bati dari penguatan umpan balik atau menaikkan orde dari tapis umpan balik. Perancangan penguat kelas D dengan umpan balik ini ditekankan pada perancangan tapis lolos bawah orde 2 tipe Butterworth. Pada penelitian ini dirancang tapis aktif lolos bawah orde 2 tipe Butterworth dengan topologi Sallen Key. Tapis aktif dipilih pada umpan balik tujuannya agar penguatan dari tapis dalam umpan balik dapat diatur. Penggunaan topologi Sallen Key dikarenakan memliki akurasi penguatan dan tepat untuk aplikasi yang memiliki faktor kualitas di bawah $3(\mathrm{Q}<3)$. Tapis yang dibuat dapat dilihat pada Gambar 3 
berikut.

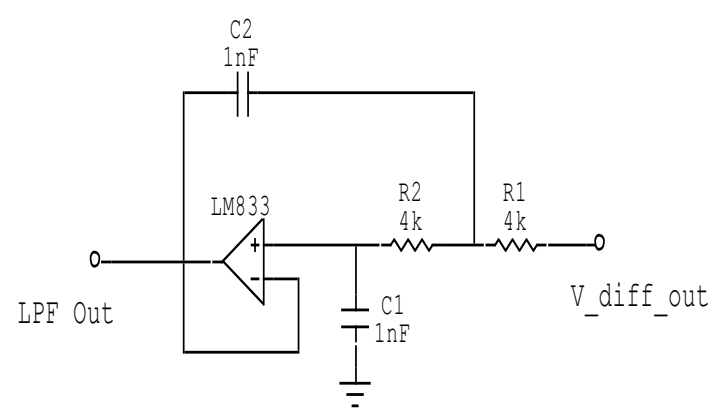

Gambar 3. Tapis Lolos Bawah Orde Dua dengan Topologi Sallen Key.

Pendekatan tapis Butterworth orde 2 memiliki koefisien tapis $a_{1}=1,4142$ dan $b_{1}=1$. Pendekatan Butterworth digunakan karena tapis ini memliki penguatan yang rata pada pita lolosnya dan memiliki respon fase sangat halus karena hal ini penting ketika mempertimbangkan distorsi [8]. Untuk menentukan nilai dari komponen tapis Butterworth yaitu dengan menentukan frekuensi penggalnya. Tapis yang dirancang memiliki frekuensi penggal sebesar 28 $\mathrm{kHz}$ dengan penguatan sama dengan 1 (unitygain). Tujuannya agar besar penguatan pada frekuensi $20 \mathrm{~Hz}-20 \mathrm{kHz}$ tetap sama dan mencegah ketidak stabilan sistem umpan balik. Perhitungan nilai komponen pada Gambar 3, ditentukan terlebih dahulu nilai kapasitor $\mathrm{C}_{1}=1$ $\mathrm{nF}$, maka nilai $\mathrm{C}_{2}$ berdasarkan persamaan (2).

$$
C_{2} \geq C_{1} \frac{4 b_{1}}{a_{1}{ }^{2}} \Rightarrow C_{2} \geq 1 \times 10^{-9} \frac{(4 \times 1)}{1,4142^{2}}=2 n F
$$

\subsection{Integrator}

Hasil keluaran dari tapis umpan balik kemudian dijumlahkan dengan sinyal audio aslinya dengan menggunakan integrator. Integrator biasanya merupakan tapis lolos bawah, sehingga frekuensi-frekuensi tinggi dapat lebih ditekan. Sinyal keluaran setelah tapis Butterworth memiliki beda fase $90^{\circ}$ terhadap sinyal sinyal audio. Sehingga proses penjumlahan masukan sinyal dari integrator (summing integrator) efektifnya mengurangi sinyal keluaran integrator untuk mendapatkan sinyal kesalahan [9]. Bentuk rangkaian dari integrator penjumlah dapat dilihat pada Gambar 4 berikut. Frekuensi penggal dari integrator dibuat $28 \mathrm{kHz}$ sama dengan tapis Butterworth tujuannya agar beda fasenya kecil antara sinyal umpan balik dan sinyal audio aslinya. Penguatan dari integrator juga dibuat 1 untuk menjaga kestabilan dari umpan balik.

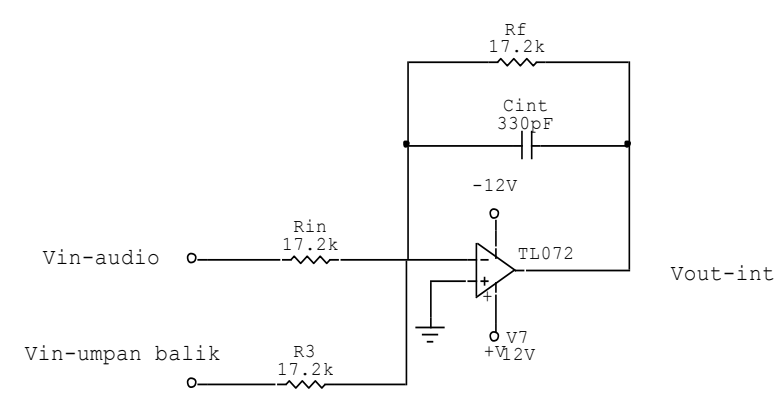

Gambar 4. Integrator Penjumlah.

Perhitungan nilai komponen dari integrator jika frekuensi penggal yang diinginkan $28 \mathrm{kHz}$ dengan besar $\mathrm{C}_{\mathrm{int}}=330 \mathrm{pF}$ maka,

$$
R=\frac{1}{2 \pi C f_{C}}=17,2 \mathrm{k} \Omega
$$

\section{HASIL DAN PEMBAHASAN}

Pengujian ini bertujuan untuk mengukur kinerja dari penguat kelas $\mathrm{D}$ dengan umpan balik tipe Butterworth. Pengujian dan pengukuran dari penguat kelas D menggunakan acuan Guidelines for Measuring Audio Power Amplfier Performance [10] dan Audio Power Amplifier Operation and Measurement [11]. Pengukuran kinerja dari penguat kelas menggunakan beban 8 Ohm. Beberapa pengujian dan pengukuran penguat kelas $\mathrm{D}$ yang dibuat adalah sebagai berikut:

\subsection{Tanggapan Frekuensi}

Pengukuran tanggapan frekuensi sinyal menggunakan bantuan perangkat lunak SpectraLab v4.32.17. Sinyal uji berupa derau putih (white noise) alasannya karena derau putih memiliki spektrum daya yang sama besar pada rentang frekuensi audio. Hasil tanggapan frekuensi penguat kelas D yang dibuat dapat dilihat pada Gambar 5. 


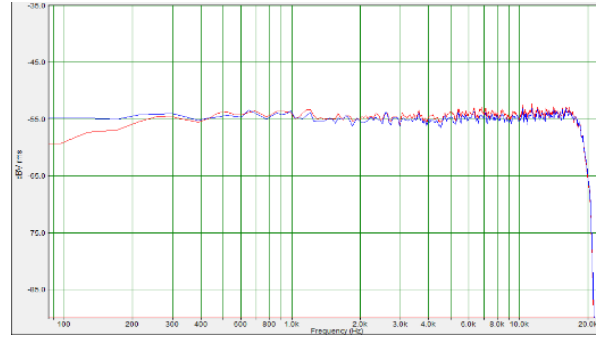

Gambar 5. Grafik Tanggapan Frekuensi (Merah: Sinyal Acuan dan Biru: Sinyal Keluaran).

Sinyal acuan yang dihasilkan pada loopback kartu bunyi digambarkan dengan warna merah, dan hasil sinyal keluaran digambarkan dengan warna biru. Dari hasil pengujian tersebut tanggapan frekuensi dari sinyal keluaran cukup rata dengan toleransi \pm 1 $\mathrm{dB}$.

\subsection{Daya Keluaran}

Pengukuran daya keluaran maksimum dari penguat kelas D menggunakan multimeter digital (DMM FLUKE 26III) dan osiloskop (GDS-820S). Sinyal masukan berupa sinusoidal dengan frekuensi $1 \mathrm{kHz}$ dengan amplitudo yang diubah-ubah untuk mendapatkan daya maksimum. Hasil pengukuran dapat dilihat pada Gambar 6.

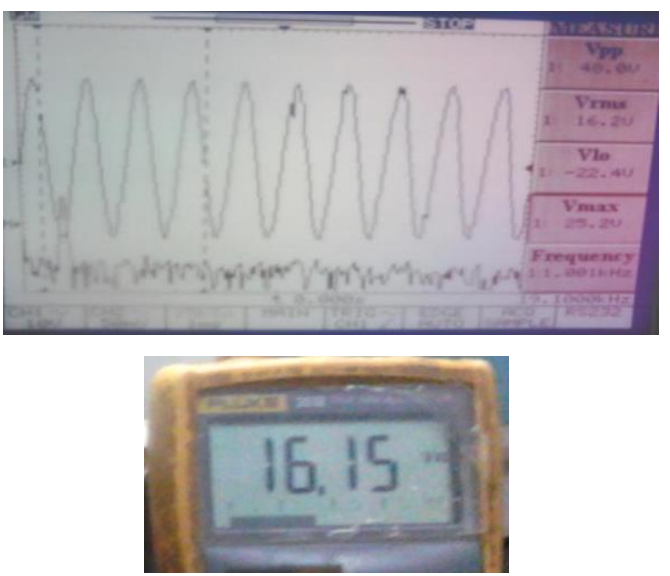

Gambar 6. Pengukuran Daya Keluaran.

Dari hasil pengukuran pada Gambar 6 tegangan rms maksimum pada beban adalah $16,15 \mathrm{~V}_{\text {rms. }}$ Daya maksimum yang dihasilkan adalah 32,6 Watt dengan perhitungan sebagai berikut :

$P_{o}(W)=\frac{V_{o(r m s)}^{2}}{R_{\text {beban }}}=\frac{(16,15)^{2}}{8}=32,6 \mathrm{~W}$

\subsection{Efisiensi}

Pengukuran efisiensi adalah total daya pada yang diterima oleh beban, pada daya yang diberikan oleh catu daya. Pengukuran efisiensi dilakukan pada saat daya keluaran maksimum. Penguat kelas D yang dibuat menggunakan 2 buah catu daya yaitu catu daya $\pm 12 \mathrm{~V}$ dan $24 \mathrm{~V}$. Catu daya $\pm 12 \mathrm{~V}$ digunakan untuk komponenkomponen sebelum penguat daya seperti bagian modulator, integrator, pembangkit gelombang segitiga, penguat Op-Amp, switching logic dan driver MOSFET. Sedangkan catu daya $24 \mathrm{~V}$ digunakan untuk MOSFET sebagai penguat daya yang dikonfigurasikan dengan jembatan penuh. Hasil pengukuran daya masukan dapat ditabelkan sebagai berikut.

Tabel 1. Hasil Pengukuran Daya Masukan

\begin{tabular}{|c|c|c|}
\hline $\begin{array}{c}\text { Catu Daya } \\
(\mathbf{V})\end{array}$ & $\begin{array}{c}\text { Arus } \\
\text { Keluaran (A) }\end{array}$ & $\begin{array}{c}\text { Daya } \\
(\mathbf{W})\end{array}$ \\
\hline+12 & 0,12 & 1,44 \\
\hline-12 & 0,04 & 0,48 \\
\hline+24 & 1,574 & 37,78 \\
\hline \multicolumn{2}{|c|}{ Total Daya } & $\mathbf{3 9 , 6 9}$ \\
\hline
\end{tabular}

Sehingga, besar efisiensi yang didapat ketika daya keluaran maksimum adalah:

$$
\eta(\%)=\frac{P_{\text {out }}}{P_{\text {in }}} \times 100 \%=\frac{32,6}{39,69} \times 100 \%=82,11 \%
$$

\subsection{Kepekaan (Sensitivity)}

Pengukuran kepekaan adalah pengukuran amplitudo masukan yang dibutuhkan penguat untuk menghasilkan daya keluaran maksimum ketika tingkat kekerasan penguat (volume) maksimum. Hasil pengukuran dapat dilihat pada Gambar 7.

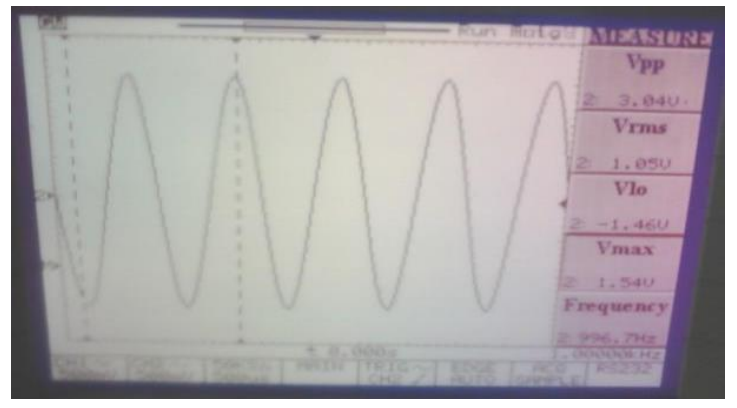

Gambar 7. Pengukuran Masukan Ketika Daya Maksimum. 
Berdasarkan hasil pengukuran didapatkan tegangan masukan sebesar $3,04 \mathrm{~V}$, artinya kepekaan penguat adalah $0,093 \mathrm{~V} / \mathrm{W}$ atau 93 $\mathrm{mV} / \mathrm{W}$.

\subsection{Total Harmonic Distortion (THD)}

Pengukuran THD adalah pengukuran total tegangan rms dari harmonisa yang dihasilkan penguat terhadap tegangan rms fundamental yang dihasilkan penguat. Pengukuran THD menggunakan sinyal sinusoidal sebagai sinyal uji. Pengukuran THD dari penguat dilakukan dalam 2 tahapan yaitu pengukuran penguat tanpa umpan balik dan dengan umpan balik. Masingmasing tahapan dilakukan 2 kali pengukuran, pertama yaitu pengukuran THD terhadap frekuensi pada daya keluaran 1 Watt dengan frekuensi masukan yang diubah-ubah. Yang kedua adalah pengukuran THD terhadap daya keluaran pada frekuensi $1 \mathrm{kHz}$. Pengukuran THD menggunakan sinyal sinusoidal sebagai sinyal uji. Hasil pengukuran THD terhadap frekuensi dapat dilihat pada Gambar 8 berikut.

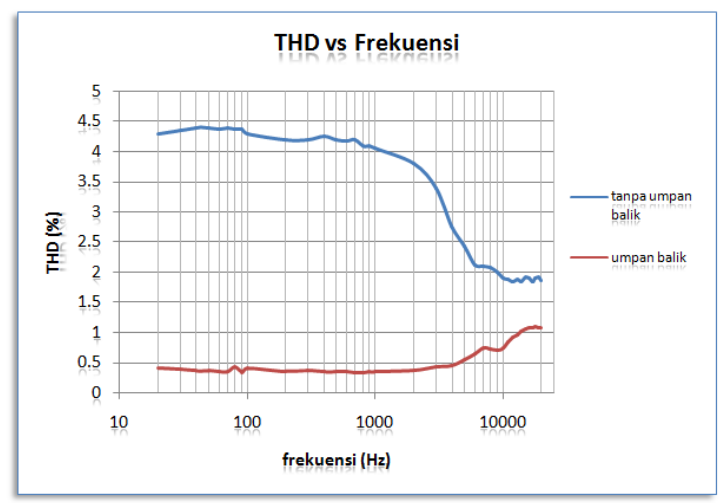

Gambar 8. Grafik Pengukuran THD Terhadap Frekuensi.

Dari Gambar 8 didapatkan bahwa THD dapat berkurang dengan memberikan umpan balik. Pada frekuensi kurang dari $4 \mathrm{kHz}$, THD yang dihasilkan $<0,5 \%$ dan THD mulai naik untuk frekuensi di atas $5 \mathrm{kHz}$. Besar THD terbesar yang terukur adalah $1,08 \%$ pada frekuensi $18 \mathrm{kHz}$. Pengukuran yang kedua adalah pengukuran THD terhadap daya keluaran ketika frekuensi sinyal masukan $1 \mathrm{kHz}$. Hasil pengukuran dapat dilihat pada Gambar 9 berikut.

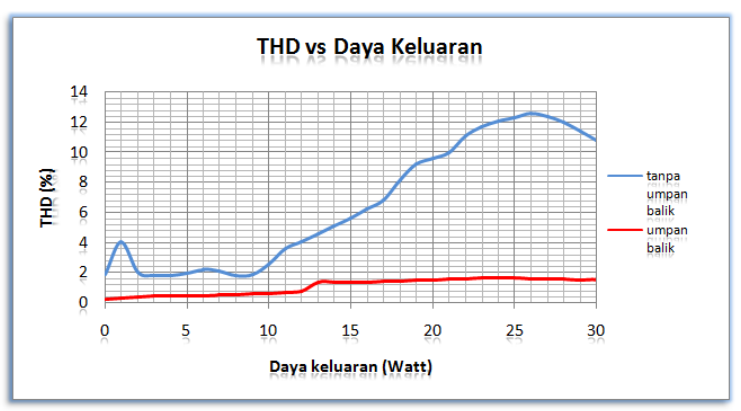

Gambar 9. Grafik Pengukuran THD Terhadap Daya Keluaran.

\subsection{Signal to Noise Ratio (SNR)}

Pengukuran SNR bertujuan untuk mendapatkan karakteristik penguat kelas D terhadapat derau yang timbul. Pengukuran dilakukan 2 kali yaitu dengan memberikan masukan berupa sinyal sinusoidal $1 \mathrm{kHz}$ dan masukan yang ditanahkan ketika daya keluaran maksimum. Hasil pengukuran SNR dapat dilihat pada gambar berikut.
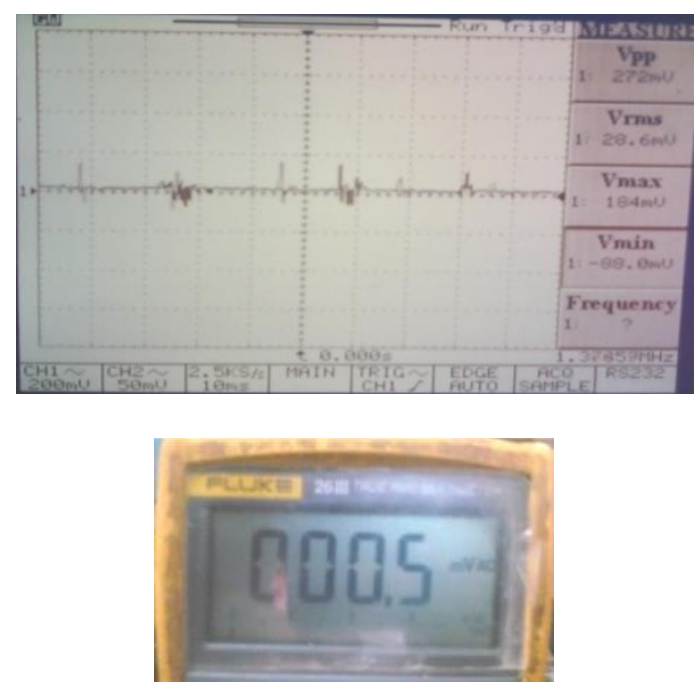

Gambar 10. Pengukuran Tegangan Keluaran saat Masukan Ditanahkan.

Berdasarkan hasil pengukuran di atas, maka besar SNR yang penguat adalah:

$$
S N R(d B)=20 \log \frac{16,16}{\left(0,5 \times 10^{-3}\right)}=90,19 d B
$$

\section{KESIMPULAN}

Penguat audio kelas D dengan umpan balik tipe Butterworth telah berhasil direalisasikan. 
Berdasarkan hasil pengujian, penguat kelas D mempunyai spesifikasi sebagai berikut ini:

1. Tanggapan frekuensi penguat $20 \mathrm{~Hz}-20 \mathrm{kHz}$ dengan toleransi $\pm 1 \mathrm{~dB}$

2. Daya maksimum 32,6 Watt pada beban $8 \Omega$.

3. Efisiensi penguat $82,11 \%$.

4. Kepekaan penguat $0,093 \mathrm{~V} / \mathrm{W}$.

5. Mempunyai THD $<1,08 \%$ pada daya keluaran 1 Watt.

6. SNR sebesar 90,16 dB.

Berdasarkan pengujian dapat dilihat bahwa umpan balik dapat memperbaiki kualitas THD dari penguat audio. Beberapa faktor yang menyebabkan THD masih cukup besar adalah penggunaan komponen yang kurang baik dalam perancangan penguat kelas $\mathrm{D}$ ini akan tetapi dengan THD sebesar 1,08 \% sudah mencukupi untuk bidang audio analog.

\section{DAFTAR PUSTAKA}

[1] Honda, J., and Adams J., Class D Audio Amplifier Basics, El Segundo, California: International Rectifier (2005).

[2] Honda, J., and Adams J., Class D Amplifier Design Basic II Rev 1.0, El Segundo, California: International Rectifier (2009).

[3] Santoso, S., Penguat Audio Kelas D tanpa Tapis LC dengan Modulasi Tiga Aras, Skripsi S1 Universitas Kristen Satya Wacana (2012).

[4] Morey, B.,Vasudeyan, R., and Woloschin I., Class D Audio Amplifier: The Design of A Live Audio Class D Audio Amplifier with Greater Than 90\% Efficiency and Less Than 1\% Distortion, A Major Qualifying Project, Faculty of the Worcester Polytechnic Institute (2008).

[5] Oliva, A. R., Ang, S. S., and Vo, T. V., A multi-loop voltage-feedback filterless class-D switching audio amplifier using unipolar pulse-width-modulation, IEEE T. Consum. Electronics 50, no. 1, 312 319 (2004).

[6] Foong, H. C. and Tan, M. T., An analysis of THD in class $D$ amplifier, IEEE Asia Pacific Conference on Circuit and Systems (2006).

[7] Chang, J. S., Gwee, B. H., Lon, Y. S. and Tan, M. T., A novel low-power lowvoltage class $D$ amplifier with feedback for improving $T H D$, power efficiency and gain linearity, IEEE International Symposium on Circuit and Systems, (2001).

[8] Quek, Y. B., Class D LC Filter Design, Dalas, Texas: Texas Instrument (2008).

[9] Leach, W. M., Introduction to Electroacoustic and Audio Amplifier Design, ed. 2, Iowa, USA: Kendal/Hunt Publishing Co. (2001).

[10] Palmer, R., Guidelines for Measuring Audio Power Amplifier Performance, Dalas, Texas: Texas Instrument (2001).

[11] Crump, S., Audio Power Amplifier (APA) Operation and Measurement, Audio Power Amplifier Application, Dalas, Texas: Texas Instrument (2010).

\section{Biodata Penulis}

Gunawan Dewantoro, ST, M.Sc.Eng, lahir di Yogyakarta pada tahun 1985. Menamatkan pendidikan S1 di Teknik Elektro Universitas Gadjah Mada, Yogyakarta pada tahun 2008. Pendidikan S2 diselesaikan di National Taiwan University of Science and Technology pada tahun 2011 dengan bidang automasi dan kendali. Masuk sebagai dosen tetap di UKSW pada tahun 2012.

Ir. F. Dalu Setiaji, MT, menamatkan S1 di Universitas Kristen Satya Wacana (UKSW), Salatiga pada tahun 1996. Pendidikan S2 diselesaikan di Teknik Elektro Universitas Gadjah Mada pada tahun 2006. Bidang peminatannya adalah untai mikroelektronika dan sistem adaptif.

Tio Pragustha, ST, menerima gelar sarjana dari Fakultas Teknik Elektronika dan Komputer Universitas Kristen Satya Wacana (UKSW) Salatiga pada tahun 2014. Bidang keahliannya adalah teknik elektronika dan elektroakustika. 